\title{
Impact of Admission Glycosylated Hemoglobin A1c on Angiographic Characteristics and Short Term Clinical Outcomes of Nondiabetic Patients with Acute ST-Segment Elevation Myocardial Infarction
}

\author{
Islam El-sherbiny, ${ }^{1}$ Baher Nabil, ${ }^{1}$ Tamer Saber, ${ }^{2}$ and Fathy Elsayed Abdelgawad ${ }^{3}$ \\ ${ }^{1}$ Cardiology Department, Faculty of Medicine, Zagazig University, Zagazig 44519, Egypt \\ ${ }^{2}$ Internal Medicine Department, Faculty of Medicine, Zagazig University, Zagazig 44519, Egypt \\ ${ }^{3}$ Medical Biochemistry Department, Faculty of Medicine, Al-Azhar University, Cairo 11651, Egypt \\ Correspondence should be addressed to Tamer Saber; tsaber7@gmail.com
}

Received 23 June 2015; Revised 10 October 2015; Accepted 16 November 2015

Academic Editor: Terrence D. Ruddy

Copyright (C) 2015 Islam El-sherbiny et al. This is an open access article distributed under the Creative Commons Attribution License, which permits unrestricted use, distribution, and reproduction in any medium, provided the original work is properly cited.

\begin{abstract}
We aimed to assess the predictive value of admission HbAlc level in nondiabetic patients presented by acute STEMI, on outcome of PCI and short term outcome of adverse cardiac events. Methods. 60 nondiabetic patients were admitted to Cardiology Department, Zagazig University Hospital, with acute STMI: 27 patients with HbAlc levels of 4.5\% to 6.4\% (group 1), 17 patients with HbAlc levels of $6.5 \%$ to $8.5 \%$ (group 2), and 16 patients with HbAlc levels higher than $8.5 \%$ (group 3). Either invasive intervention was done at admission by (pPCI) or coronary angiography was done within month (3-28 days) from taking thrombolytic. Participants were followed up for 6 months. Results. There was significant difference among different groups of HbAlc as regards the number of diseased vessels, severity of CAD lesions ( $p$ value $<0.01$ ), and TIMI flow grades ( $p$ value $<0.05$ ). There was significant difference among different groups as regards the adverse cardiac events on short term follow-up period ( $p$ value $<0.05$ ). Conclusion. The present study showed that admission higher HbAlc level in patients presented by acute STEMI is associated with more severe $\mathrm{CAD}$, lower rate of complete revascularization, and higher incidence of adverse cardiac events.
\end{abstract}

\section{Introduction}

Stress hyperglycemia in ST-segment elevation myocardial infarction (STEMI) patients was found to be associated with significantly increased rates of mortality and congestive heart failure and shock [1-3]. Most of these studies, however, were in trials of fibrinolytic therapy; conversely the evidence linking hyperglycemia with an adverse prognosis in patients treated with primary percutaneous coronary intervention (pPCI) is limited and derived mainly from observational registries [4].

In acute myocardial infraction (AMI), stress hyperglycemia commonly occurs secondary to increased catecholamine levels, so looking only at plasma glucose levels at the time of an AMI cannot predict the prognosis [5]. Glycosylated hemoglobin Alc (HbAlc) is a measure of the average blood glucose levels over 2 months [6] and is minimally affected by acute hyperglycemia often observed in myocardial infarction (MI).

Elevated $\mathrm{HbAlc}$ is an important determinant of atherosclerosis beyond the risk associated with established diabetes [7].

Aim of the Work. Our study aimed to assess the predictive value of admission HbAlc level in nondiabetic patients presented to Zagazig University Hospital by acute STEMI, on outcome of pPCI and short term outcome of adverse cardiac events. 


\section{Patients and Method}

We performed a single-center, observational prospective study of sixty nondiabetes patients with acute STEMI, candidate for reperfusion therapy admitted to Cardiology Department, Zagazig University Hospital, between January 2013 and December 2013.

2.1. Inclusion Criteria. Confirmed admission diagnosis of acute STEMI, within $12 \mathrm{~h}$ of symptom onset and with persistent ST-segment elevation or new or presumed new $\mathrm{LBBB}$, early mechanical pPCI, or pharmacological reperfusion should be performed as early as possible.

2.2. Exclusion Criteria. Patients with passed time MI, patients who have undergone rescue PCI, patients who have contraindication to dye as dye allergy and chronic kidney disease, patients with liver cell failure, haemoglobinopathies, haemolytic anaemia, chronic malaria, or severe iron deficiency anaemia due to giving unreliable results leading to inaccurate HbAlc level, and patients with past history of diabetes or on antidiabetic treatment were excluded.

2.3. Clinical Data and Blood Samples. Main demographic data and the five major risk factors obesity, history of hypertension, dyslipidemia, family history, and cigarette smoking were carefully evaluated.

$\mathrm{HbAlc}$ levels of all patients were measured within 3 hours of admission, using Siemens DCA analyzer for quantitative assay for HbAlc in blood. Both the concentrations of HbAlc specifically and the concentration of total hemoglobin are measured and the ratio reported as percent HbAlc. All of the reagents for performing both reactions are contained in the DCA HbAlc cartridge [8] and using a method which is National Glycohemoglobin Standardization Program (NGSP) [9].

Patients were divided into three groups according to the level of HbAlc with cut-off $6.5 \%$ as a diagnostic criteria of diabetes mellitus according to (2010) ADA Diagnosis and Classification of Diabetes Mellitus [10]: 27 patients with HbAlc levels of $4.5 \%$ to $6.4 \%$ (group 1), 17 patients with HbAlc levels of $6.5 \%$ to $8.5 \%$ (group 2), and 16 patients with $\mathrm{HbAlc}$ levels higher than $8.5 \%$ (group 3 ).

2.4. Angiography. Either invasive intervention was done at admission by pPCI or coronary angiography was done within month (3-28 days) from taking thrombolytic in stable asymptomatic patients according to the best evidence based medicine [11, 12]. 45 cases were subjected to pPCI and 15 cases received thrombolytic. For pPCI wiring culprit artery based upon ECG, revascularization of culprit artery only was done unless patient is in cardiogenic shock [13]. We used the visual method for evaluation and assessment of number of significantly diseased coronary arteries, with special focus on infracted related artery (guided by ECG) on type of the lesion either type A, B, or C [14]. Also, we used TIMI flow grading system in pPCI cases [15]. Angiographic results were interpreted by two angiographers who were

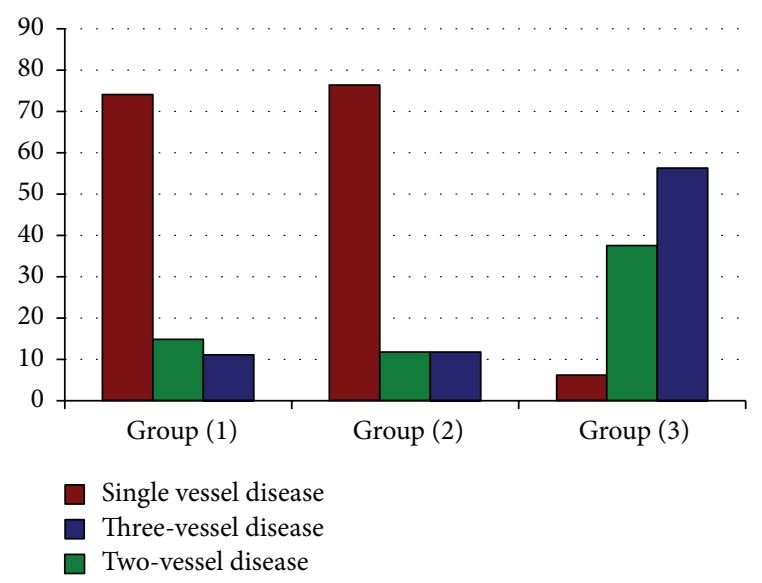

FIGURE 1: Number of diseased vessels in the study groups $(1,2$, and $3)$.

blinded to clinical or demographic data. The study protocol was approved by the institutional ethics committee and all patients provided written, informed consent before study entry.

2.5. Follow-Up Period. Follow-up for six months after the onset of MI mainly for (1) heart failure, (2) reinfarction, and (3) mortality was through phone calls followed by hospital visit in outpatient clinic.

2.6. Statistical Analysis. Statistical presentation and analysis of the present study were conducted, using the mean, standard deviation, analysis of variance (ANOVA) test, and chisquare test by SPSS V 21, Student's $t$-test was used to test the significance of the difference between two independent sample means; value of $<0.05$ indicates significant results.

\section{Results}

Baseline clinical characteristics and angiographic data regarding number of diseased vessels and lesion type are shown in Table 1 . There was no significant difference between the three groups regarding age, sex, hypertension, smoking, family history, and obesity ( $p$ value $>0.05$ ).

Regarding number of diseased vessels, there was high statistically significant difference between the three groups ( $p$ value $<0.001$ ), Figure 1 .

There was high statistically significant difference between the three groups regarding lesion types $\mathrm{A}, \mathrm{B}$, and $\mathrm{C}$ ( $p$ value 0.000 ), Figure 2.

Table 2 shows significant difference among different groups of HbAlc as regards the degree of successful reperfusion. This was supported by the significant difference among different groups as regards TIMI flow grades with higher percentage of TIMI grade 3 in group 1 and higher percentage of TIMI grade 1 in favor of group 3 ( $p$ value $<0.05$ ), Figure 3. Also as shown in Table 2 patients in group 1 have higher rates of TIMI flow grade $0(16.7 \%)$ as compared to group 2 (5.9\%) and group 3 (10\%). 
TABLE 1: Baseline clinical and angiographic data of patients according to HbAlc.

\begin{tabular}{|c|c|c|c|c|}
\hline \multicolumn{5}{|c|}{ Level of glycosylated hemoglobin } \\
\hline & $\begin{array}{c}\text { Group (1) } \\
<6.5 \% \\
(n=27)\end{array}$ & $\begin{array}{c}\text { Group (2) } \\
6.5 \%-8.5 \% \\
(n=17)\end{array}$ & $\begin{array}{c}\text { Group (3) } \\
>8.5 \% \\
(n=16)\end{array}$ & $p$ value \\
\hline Age, years (mean \pm SD) & $57.9 \pm 10.2$ & $58.3 \pm 7.1$ & $57.3 \pm 8.5$ & NS \\
\hline Sex, $n$ (male/female) & $23 / 4$ & $13 / 4$ & $12 / 4$ & NS \\
\hline Smoking, \% & $55.6 \%$ & $47.1 \%$ & $37.5 \%$ & NS \\
\hline Hypertension, \% & $48.1 \%$ & $47.1 \%$ & $68.8 \%$ & NS \\
\hline Obesity $\left(\mathrm{BMI}>30 \mathrm{~kg} / \mathrm{m}^{2}\right), \%$ & $22.2 \%$ & $17.6 \%$ & $25 \%$ & NS \\
\hline Family history & $11.1 \%$ & $11.7 \%$ & $18.8 \%$ & NS \\
\hline \multicolumn{5}{|c|}{ Angiography (number of diseased vessels), $n$ (\%) } \\
\hline Single vessel & $20(74.1 \%)$ & $13(76.4 \%)$ & $1(6.2 \%)$ & 0.000 \\
\hline Double vessel & $4(14.8 \%)$ & $2(11.8 \%)$ & $6(37.5 \%)$ & 0.12 \\
\hline Triple vessel & $3(11.1 \%)$ & $2(11.8 \%)$ & $9(56.3 \%)$ & 0.001 \\
\hline \multicolumn{5}{|c|}{ Lesion type, $n(\%)$} \\
\hline A & $19(70.4 \%)$ & $6(35.3 \%)$ & $3(18.8 \%)$ & \multirow{3}{*}{0.000} \\
\hline B & $5(18.5 \%)$ & $9(52.9 \%)$ & $3(18.8)$ & \\
\hline $\mathrm{C}$ & $3(11.1 \%)$ & $2(11.8 \%)$ & $10(62.5 \%)$ & \\
\hline
\end{tabular}

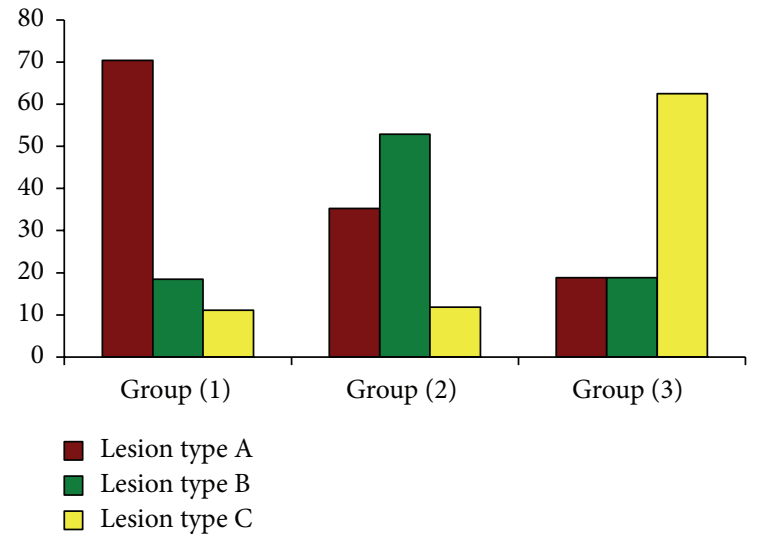

FIGURE 2: Lesion type in relation to the study groups according to HbAlc.

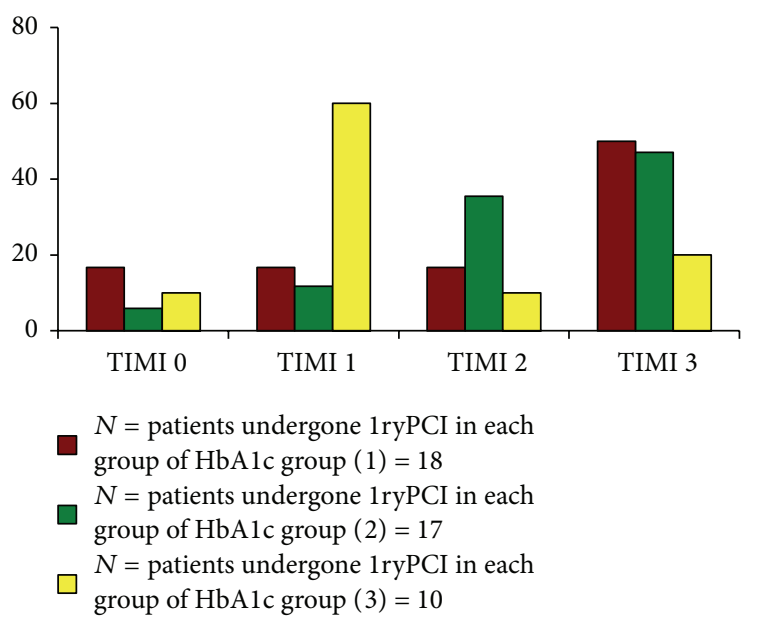

Figure 3: TIMI flow grade in primary PCI cases $(n=45)$.
TABLE 2: TIMI flow grade in primary PCI cases $(n=45)$.

\begin{tabular}{lccccc}
\hline & TIMI 0 & TIMI 1 & TIMI 2 & TIMI 3 & Sig. \\
\hline $\begin{array}{l}\text { Group (1) } \\
(N=18)\end{array}$ & $(3) 16.7 \%$ & (3) $16.7 \%$ & (3) $16.7 \%$ & (9) $50 \%$ & \\
$\begin{array}{l}\text { Group (2) } \\
(N=17)\end{array}$ & $(1) 5.9 \%$ & (2) $11.8 \%$ & (6) $35.5 \%$ & (8) $47.1 \%$ & 0.04 \\
$\begin{array}{l}\text { Group (3) } \\
(N=10)\end{array}$ & (1) $10 \%$ & (6) $60 \%$ & (1) $10 \%$ & (2) $20 \%$ & \\
\hline
\end{tabular}

TABLE 3: Adverse cardiac events in the study groups according to HbAlc.

\begin{tabular}{lcccc}
\hline \multicolumn{5}{c}{ Level of glycosylated hemoglobin } \\
$\begin{array}{l}\text { Adverse } \\
\text { cardiac } \\
\text { events }\end{array}$ & $\begin{array}{c}\text { Group (1) } \\
<6.5 \%\end{array}$ & $\begin{array}{c}\text { Group (2) } \\
6.5 \%-8.5 \%\end{array}$ & $\begin{array}{c}\text { Group (3) } \\
(n=8.5 \%\end{array}$ & p value \\
$(n=27)$ & $(n=17)$ & $(n=16)$ & \\
\hline Reinfarction & $(2)$ & $(1)$ & $(2)$ & \\
& $7.4 \%$ & $5.9 \%$ & $12.5 \%$ & \\
Mortality & $(2)$ & $(2)$ & $(6)$ & \\
& $7.4 \%$ & $11.8 \%$ & $37.5 \%$ & 0.04 \\
Heart & $(1)$ & $(1)$ & $(2)$ & \\
failure & $3.7 \%$ & $5.9 \%$ & $12.5 \%$ & \\
No cardiac & $(22)$ & $(13)$ & $(6)$ & \\
events & $81.5 \%$ & $76.5 \%$ & $37.5 \%$ & \\
\hline
\end{tabular}

Adverse cardiac events on short term follow-up period were shown in Table 3; statistically significant difference among different groups of HbAlc with higher mortality, reinfarction, and heart failure in group 3 ( $p$ value $<0.05)$ is shown in Figure 4. A multiregression analysis in the present 


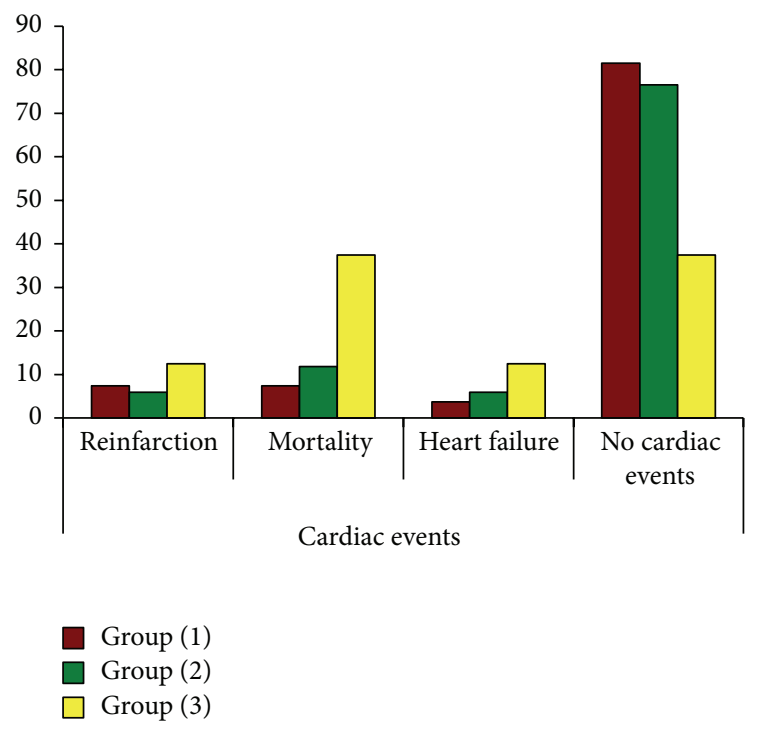

Figure 4: Adverse cardiac events in the study groups (1, 2, and 3).

study confirmed that HbAlc over $6.5 \%$ is an independent predictor outcome of adverse cardiac events.

\section{Discussion}

In acute myocardial infraction (AMI), stress hyperglycemia commonly occurs secondary to increased catecholamine levels, so looking only at plasma glucose levels at the time of an AMI cannot predict the prognosis [5]. Glycosylated hemoglobin Alc ( $\mathrm{HbAlc})$ is a measure of the average blood glucose levels over 2 months [6] and is minimally affected by acute hyperglycemia often observed in myocardial infarction (MI).

In the present study there was significant difference among different $\mathrm{HbAlc}$ groups as regards the number of diseased coronary vessels with higher percentage of threevessel disease, better than higher number of three-vessel disease in group (3). This was concordant with previous studies by Cakmak et al. [16] and Kassaian et al. [17]. This can be explained by insulin resistance in hyperglycemia promoting molecular mechanism by Advanced Glycation End Products (AGEs) which are intimately involved in the pathophysiology of cardiovascular disease by stimulating inflammation, contributing to atheroma formation modulating vascular stiffness and the disturbed endothelial function by reduction of nitric oxide release and increased vascular smooth muscle proliferation [18] and increase of HbAlc one percent is associated with 2.8-fold increase in CAD and in severity of coronary artery lesions, beyond high risk profile of those patients; it is worth mentioning that even HbAlc value in normal range is associated with presence and severity of CAD [19].

On the contrary, this was discordant with Ertem et al. [20] who found no significant difference between $\mathrm{HbAlc}$ level and severity of CAD. This discrepancy may be due to the different score for assessment of the severity CAD in their study or the sample size or population difference.
In the present study there was significant difference among different HbAlc groups as regards lesion type (A, B, and $C$ ) with higher lesion type $A$ in group (1) and lesion type $\mathrm{C}$ in group (3). This was in agreement with Kassaian et al. [17] who found highly significant difference among HbAlc groups as regards lesion type $\mathrm{C}$. This may be explained by the fact that diabetes is associated with more extensive coronary artery lesion, more complex lesion, more diffuse excessive tortuosity in the proximal segment, extreme angulations, and total occlusion [20].

In the present study there was significant difference among different HbAlc groups as regards TIMI flow grades in patients who had undergone pPCI, with higher percentage of TIMI 3 in group (1) and significant higher percentage of TIMI 1 in favor of group (3) and this was in agreement with Planner et al. [4]. This finding may be explained by the fact that hyperglycemia is associated with higher rate of TIMI $0 \backslash 1$ and lower rate of complete revascularization TIMI and hyperglycemia adversely affect platelets function and endothelial function, promote inflammation, and result in procoagulable condition; it is worth mentioning that hyperglycemia per se in STEMI leads to impaired coronary flow on presentation and after pPCI [4]. This goes with our finding that TIMI 3 complete revascularization is higher in group (1), the least level of HbAlc, and TIMI 1 flow has statistical significant difference between groups (1) and (3) with higher percentage in favour of group (3), the highest level of HbAlc, beyond the fact that patients with higher HbAlc on admission have larger myocardial infarction and less frequently have open infracted artery.

In the present study we assess HbAlc level on the short term outcome (six months) to detect major adverse cardiac event as mortality, heart failure, and reinfarction. In the present study there was significant difference among different $\mathrm{HbAlc}$ groups as regards adverse cardiac events; this was concordant with Cakmak et al. [16] and Kassaian et al. [17]. This may be explained by the fact that higher HbAlc level at admission was associated with worse cardiometabolic characteristics, larger infarct size, more extensive coronary artery lesion, higher percentage of TMI 1 flow, and lower rate of complete revascularization TIMI 3 flow.

\section{Conclusion}

The present study showed that admission higher HbAlc level in nondiabetic patients presented by acute STEMI is associated with more severe $\mathrm{CAD}$, lower rate of complete revascularization TIMI 3, and higher incidence of adverse cardiac events and mortality. Higher HbAlc level may be considered for risk stratification of patients presented by acute STEMI who are amenable to primary PCI, but these findings need to be verified by multicenter and larger cohort studies. In addition, this study was limited to Egyptian subjects, so conclusions for other ethnic groups are needed.

\section{Conflict of Interests}

The authors declare that there is no conflict of interests regarding the publication of this paper. 


\section{References}

[1] D. Aguilar, S. D. Solomon, L. Koøber et al., "Newly diagnosed and previously known diabetes mellitus and 1-year outcomes of acute myocardial infarction: the Valsartan in acute myocardial infarction (VALIANT) trial," Circulation, vol. 110, no. 12, pp. 1572-1578, 2004.

[2] M. Ishihara, S. Kojima, T. Sakamoto et al., "Acute hyperglycemia is associated with adverse outcome after acute myocardial infarction in the coronary intervention era," American Heart Journal, vol. 150, no. 4, pp. 814-820, 2005.

[3] M. Ishihara, "Acute hyperglycemia in patients with acute myocardial infarction," Circulation Journal, vol. 76, no. 3, pp. 563-571, 2012.

[4] D. Planer, B. Witzenbichler, G. Guagliumi et al., "Impact of hyperglycemia in patients with ST-segment elevation myocardial infarction undergoing percutaneous coronary intervention: the HORIZONS-AMI trial," International Journal of Cardiology, vol. 167, no. 6, pp. 2572-2579, 2013.

[5] G. Koraćević, S. Petrović, M. Tomašević, S. Apostolović, and M. Damjanović, "Stress hyperglycemia in acute myocardial infaraction," Facta Universitatis Series: Medicine and Biology, vol. 13, no. 3, pp. 152-157, 2006.

[6] K. H. Gabbay, K. Hasty, J. L. Breslow, R. C. Ellison, H. F. Bunn, and P. M. Gallop, "Glycosylated hemoglobins and long-term blood glucose control in diabetes mellitus," Journal of Clinical Endocrinology and Metabolism, vol. 44, no. 5, pp. 859-864, 1977.

[7] R. Naito, K. Miyauchi, M. Ogita et al., "Impact of admission glycemia and glycosylated hemoglobin Alc on long-term clinical outcomes of non-diabetic patients with acute coronary syndrome," Journal of Cardiology, vol. 63, no. 2, pp. 106-111, 2014.

[8] B. Knowles, W. Haigh, G. Michaud, and V. Marchesi, "A monoclonal antibody_based immunoassay for HbAlc," Diabetes, vol. 35, supplement 94A, 1986.

[9] R. R. Little, C. L. Rohlfing, H. M. Wiedmeyer, G. L. Myers, D. B. Sacks, and D. E. Goldstein, "NGSP Steering Comittee: the national glycohemoglobin standardization program: a five-year progress report," Clinical Chemistry, vol. 47, no. 11, pp. 19851992, 2001.

[10] American Diabetes Association, "Diagnosis and classification of diabetes mellitus," Diabetes Care, vol. 33, supplement 1, pp. S62-S69, 2010.

[11] J. S. Hochman, G. A. Lamas, C. E. Buller et al., "Coronary intervention for persistent occlusion after myocardial infarction," The New England Journal of Medicine, vol. 355, no. 23, pp. 23952407, 2006.

[12] M. Cohen, J. E. Diez, G. N. Levine et al., "Pharmacoinvasive management of acute coronary syndrome: incorporating the," Journal of Invasive Cardiology, vol. 19, no. 12, pp. 525-540, 2007.

[13] W. Wijns, P. Kolh, N. Danchin et al., "Guidelines on myocardial revascularization. Task Force on Myocardial Revascularization of the European Society of Cardiology (ESC) and the European Association for Cardio-Thoracic Surgery (EACTS); European Association for Percutaneous Cardiovascular Interventions (EAPCI)," European Heart Journal, vol. 31, no. 20, pp. 2501-2555, 2010.

[14] T. J. Ryan, D. P. Faxon, R. M. Gunnar et al., "Guidelines for percutaneous transluminal coronary angioplasty. A report of the American College of Cardiology/American Heart Association Task Force on Assessment of Diagnostic and Therapeutic Cardiovascular Procedures (Subcommittee on Percutaneous
Transluminal Coronary Angioplasty)," Circulation, vol. 78, no. 2, pp. 486-502, 1988.

[15] F. D'Ascenzo, G. Biondi-Zoccai, C. Moretti et al., "TIMI, GRACE and alternative risk scores in Acute Coronary Syndromes: a meta-analysis of 40 derivation studies on 216,552 patients and of 42 validation studies on 31,625 patients," Contemporary Clinical Trials, vol. 33, no. 3, pp. 507-514, 2012.

[16] M. Cakmak, N. Cakmak, S. Cetemen et al., "The value of admission glycosylated hemoglobin level in patients with acute myocardial infarction," Canadian Journal of Cardiology, vol. 24, no. 5, pp. 375-378, 2008.

[17] S. E. Kassaian, H. Goodarzynejad, M. A. Boroumand et al., "Glycosylated hemoglobin (HbAlc) levels and clinical outcomes in diabetic patients following coronary artery stenting," Cardiovascular Diabetology, vol. 11, article 82, 2012.

[18] A. Prasad, P. Bekker, and S. Tsimikas, "Advanced glycation end products and diabetic cardiovascular disease," Cardiology in Review, vol. 20, no. 4, pp. 177-183, 2012.

[19] H. Ashraf, M. A. Boroumand, A. Amirzadegan, S. A. Talesh, and G. Davoodi, "Hemoglobin A1C in non-diabetic patients: an independent predictor of coronary artery disease and its severity," Diabetes Research and Clinical Practice, vol. 102, no. 3, pp. 225-232, 2013.

[20] A. G. Ertem, H. Bağbancı, H. Kılıç, E. Yeter, and R. Akdemir, "Relationship between $\mathrm{HbAlc}$ levels and coronary artery severity in nondiabetic acute coronary syndrome patients," Türk Kardiyoloji Derneği Arşivi, vol. 41, no. 5, pp. 389-395, 2013. 


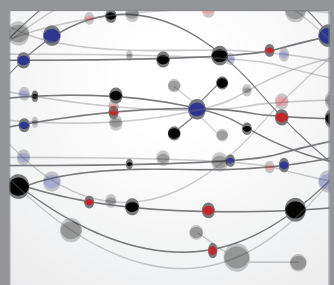

The Scientific World Journal
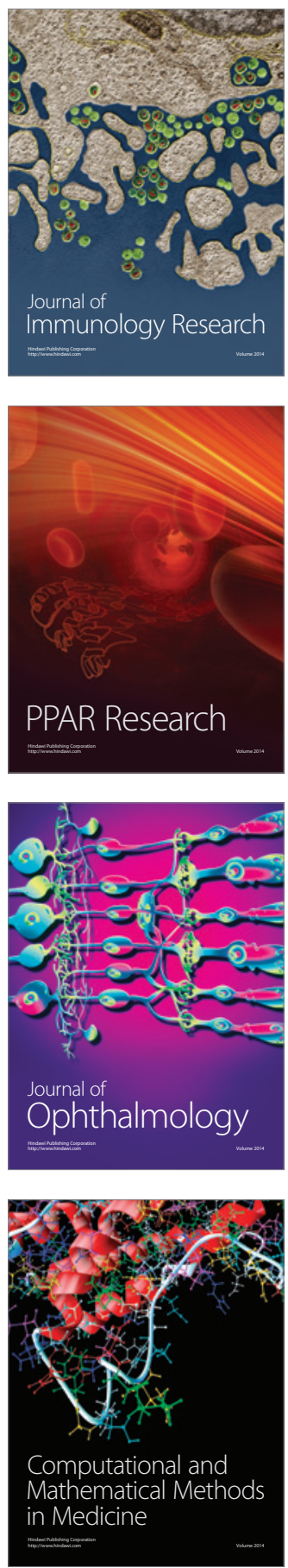

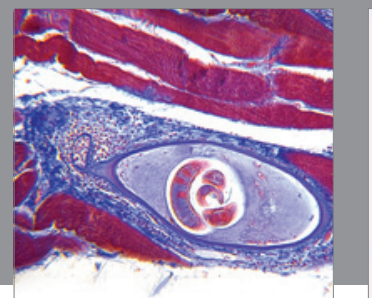

Gastroenterology

Research and Practice
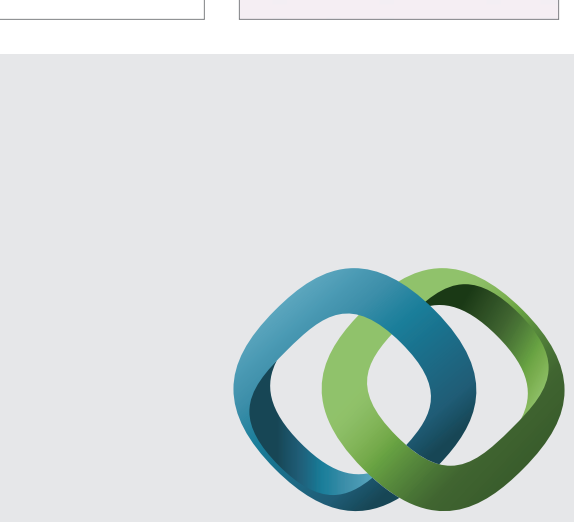

\section{Hindawi}

Submit your manuscripts at

http://www.hindawi.com
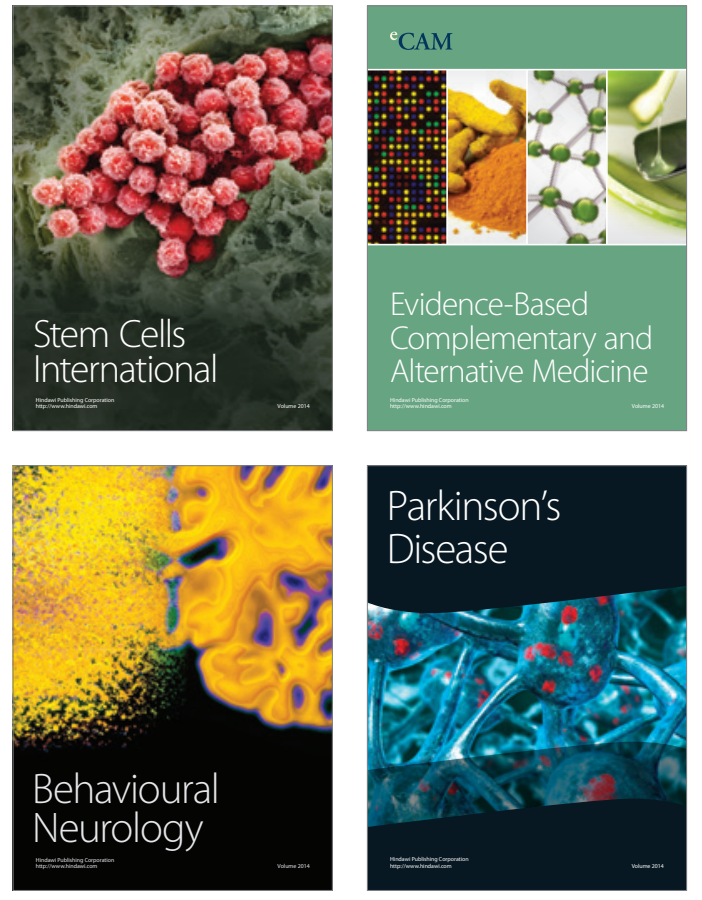
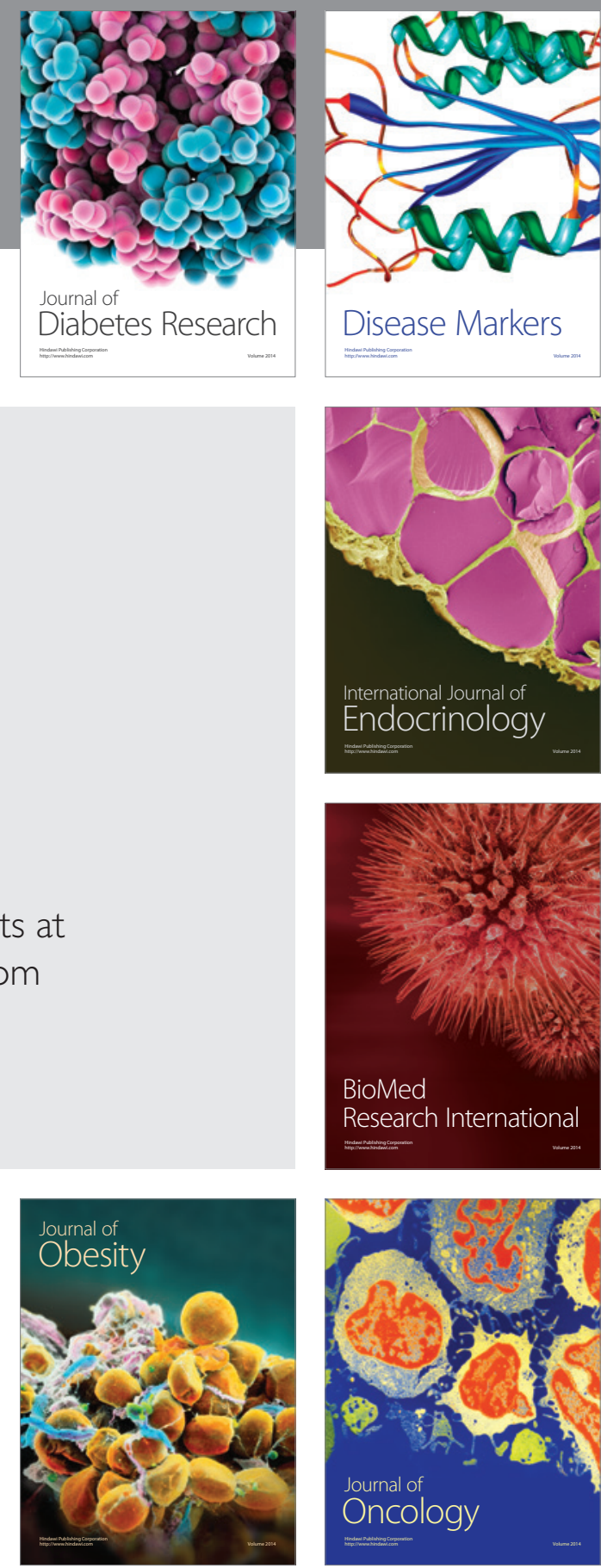

Disease Markers
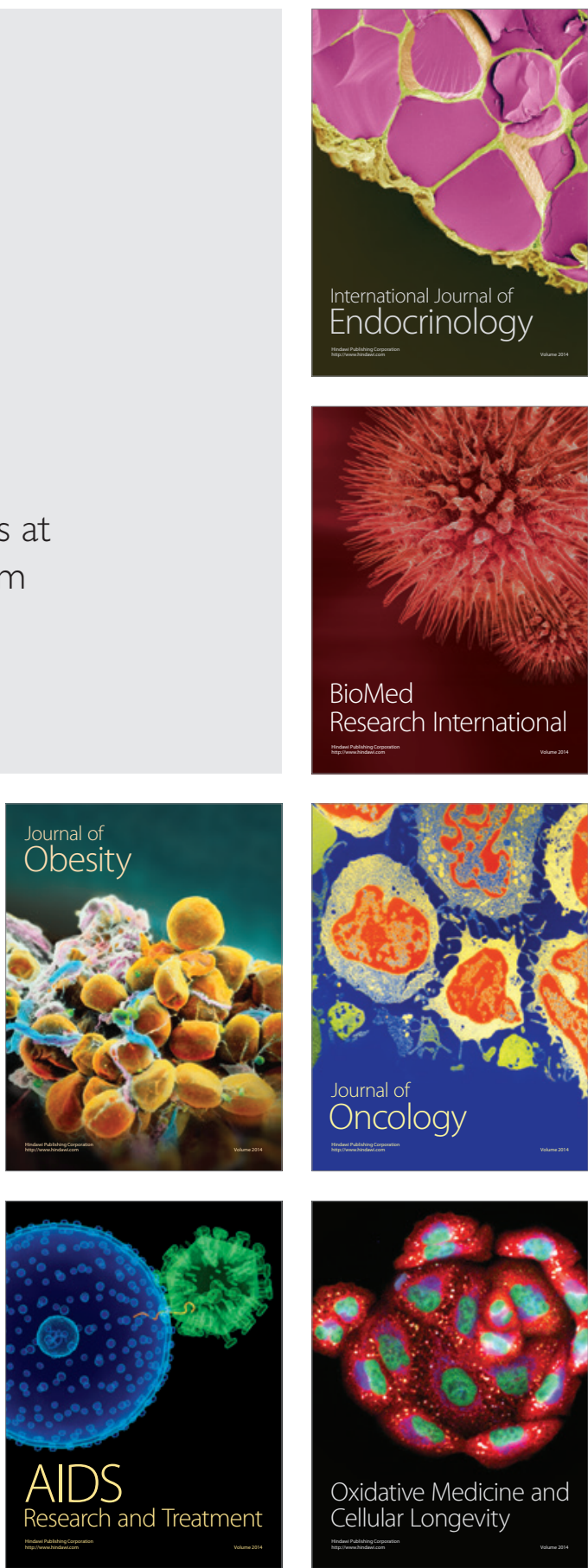